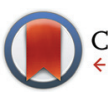

CrossMark \& click for updates

Cite this: Polym. Chem., 2015, 6 , 6171

Received 22nd May 2015,

Accepted 6th July 2015

DOI: $10.1039 / c 5 p y 00776 c$

www.rsc.org/polymers

\title{
Functional surfaces obtained from emulsion polymerization using antimicrobial glycosylated block copolymers as surfactants
}

\author{
Marta Álvarez-Paino, ${ }^{\mathrm{a}, \mathrm{b}}$ Alexandra Muñoz-Bonilla, ${ }^{\mathrm{a}, \mathrm{c}}$ Fátima López-Fabal, ${ }^{d}$ \\ José L. Gómez-Garcés, ${ }^{d}$ Johan P. A. Heuts ${ }^{\star b}$ and Marta Fernández-García ${ }^{a}$
}

\begin{abstract}
In this work, antimicrobial glycosylated block copolymers were successfully immobilized onto polymeric surfaces by using them as surfactants in butyl methacrylate emulsion polymerization. In particular several amphiphilic block copolymers of various compositions were employed, all consisting of a poly(butyl methacrylate) hydrophobic segment and a statistical copolymer containing quaternized trimethylaminoethyl methacrylate and 2-(D-glucosamin-2-N-yl)carbonylethyl methacrylate glycomonomer as a hydrophilic block. The influence of the antimicrobial polymeric surfactant structure and solid content on the emulsion polymerization was investigated in detail. It was demonstrated that the efficiency of the surfactant is highly dependent on the hydrophilic/hydrophobic balance; in general the surface-active properties get worse with an excess of hydrophilicity. Monodisperse and stable latexes stabilized with an antimicrobial polymeric surfactant were successfully obtained and then employed to form active films. The film formation process under thermal treatments was followed and confirmed by AFM. The surface functionality of the films was tested by analyzing the interaction of glycounits of the surface with Concanavalin A lectin by fluorescence spectroscopy. In addition, the antimicrobial capability of these films against Gram-positive bacteria and yeast was demonstrated whereas the leaching of the surfactants to the media was discarded.
\end{abstract}

\section{Introduction}

Antimicrobial coatings are in great demand for the prevention and inhibition of bacterial growth in and on many materials. They have found, among many applications, uses in, for example, storage containers and in the shipping industry for the prevention of marine biofouling. ${ }^{1,2}$ Of particular interest is the use of antimicrobial surfaces in medical devices. Bacterial infections from medical devices cause substantial morbidity, especially as a consequence of synthetic implants, prolonged hospitalization and regular interventions. ${ }^{3}$ In addition, the treatment of microbial infections is becoming increasingly difficult because of the growing number of antibiotic-resistant

\footnotetext{
${ }^{a}$ Instituto de Ciencia y Tecnología de Polimeros (ICTP-CSIC), Juan de la Cierva 3, 28006 Madrid, Spain

${ }^{b}$ Department of Chemical Engineering and Chemistry, Eindhoven University of Technology, P.O. Box 513, 5600 MB Eindhoven, The Netherlands

${ }^{c}$ Departamento de Quimica Física Aplicada, Facultad de Ciencias, Universidad Autónoma de Madrid, Francisco Tomás y Valiente 7, Cantoblanco, 28049 Madrid, Spain

${ }^{d}$ Hospital Universitario de Móstoles, Río Júcar, s/n, 28935 Móstoles, Madrid, Spain. E-mail: sbonilla@ictp.csic.es, j.p.a.heuts@tue.nl
}

microbial strains. Related to medical implants, i.e., prosthetics or catheters, one of the major problems is the development of biofilms on the foreign surfaces, which is responsible for a wide range of microbial infections. The first step of this extensively studied process consists of the adsorption of proteins and biomolecules to the surface creating an optimal environment for the proliferation of bacteria. ${ }^{4}$ Many different strategies have been developed for the prevention of bacterial adhesion and biofilm formation and the inhibition of bacterial growth on the surface of materials. Antifouling coatings based on hydrophilic polymers such as poly(ethylene glycol) reduce bacterial adhesion rather than kill the microorganisms, which is a very effective strategy. In order to impart a bactericidal action to a coating, traditionally low molar mass biocides such as antibiotics, halogens, or metal ions are used to impregnate a polymer matrix, often using controlled release strategies. ${ }^{5}$ There exist, however, serious concerns about these methods because the antimicrobial agents leach out of the materials, which result in not only a loss of antimicrobial properties but also a problem of residual toxicity. Nanotechnology ${ }^{6}$ and bioinspired approaches ${ }^{7}$ are currently very promising alternatives for the creation of durable antimicrobial surfaces. A large number of these strategies employ antimicrobial polymers ${ }^{8,9}$ 
offering several advantages, such as lower mobility reducing their tendency to leach out. Additionally, bacteria are less likely to develop resistance to antimicrobial polymers, because the mechanism of action relies on the destruction of the bacterial membrane instead of interference in the metabolic process. Therefore, surface modification with antimicrobial polymers is considered a very promising strategy to fabricate long term active coatings, by using, for instance, grafting approaches, ${ }^{10}$ layer by layer techniques, ${ }^{11}$ or monomers with antimicrobial groups in polyurethane coatings. ${ }^{12,13}$ Another approach that has been investigated is the preparation of coatings from latexes containing antimicrobial polymers in their formulation. Typically in this method emulsion polymerization is carried out using polymeric surfactants with special functionality, leading to the final coating with this particular functionality. This versatile and waterborne method has been previously used to achieve films decorated with carbohydrates having lectin binding abilities, ${ }^{14,15}$ and antifouling ${ }^{16}$ and antimicrobial functional groups. ${ }^{17}$ In addition to incorporating a particular functionality, the use of functional polymeric surfactants avoids the use of low molecular weight surfactants. Since these low molecular weight surfactants are generally toxic, this is of vital interest in biomedical applications. In the current study we have extended the approach of using polymeric surfactants in emulsion polymerization to the use of antimicrobial polymers with very low toxicity. In a previous study we synthesized and fully characterized block copolymers containing hydrophobic segments of poly(butyl methacrylate) and hydrophilic antimicrobial segments based on quaternized poly(2-(dimethylamino)ethyl methacrylate) and glycomonomer units with the purpose of reducing the cytotoxicity of the polymers. ${ }^{18}$ It was clearly demonstrated that the control of the glycounit content and the positive charge density are crucial to achieve a non-toxic and potent antimicrobial polymer. The aim of the current study is to evaluate the surfactant efficiency of these block copolymers in emulsion polymerization of butyl methacrylate, their capability to form films from the latex and whether they impart antimicrobial character to the films. More importantly, due to the proven low cytotoxicity of the used polymers, it is expected that the resulting coatings could be safe for biomedical applications even if undesired leaching of the polymers were to occur.

\section{Experimental part}

\section{Materials}

For the preparation of micellar solutions, $\mathrm{N}, \mathrm{N}$-dimethylformamide (DMF, Scharlau) and regenerated cellulose dialysis tubing Spectra/POR®6 $M_{\mathrm{WCO}} 3.5 \mathrm{kDa}$ were used.

The butyl methacrylate monomer (BMA, 99\%, SigmaAldrich) was purified with an inhibitor remover (SigmaAldrich) following the manufacturer's instructions. 2,2'-Azobis (2-methylpropionamidine) dihydrochloride (V-50, 97\%, SigmaAldrich) and sodium dodecyl sulfate (SDS, >99\%, Fluka) were used as received as a water-soluble initiator and a surfactant, respectively. Hydroquinone (>99\%, Sigma-Aldrich) was employed as a free radical quencher.

For fluorescence spectroscopy studies, the lectinfluorescein isothiocyanate conjugate from Canavalia ensiformis (Con A-FITC), Bovine Serum Albumin (BSA) and the buffer Trizma-HCl $\mathrm{pH} 7.4$ were purchased from Sigma-Aldrich and used as received. $\mathrm{NaCl}$ (Panreac), $\mathrm{MnCl}_{2} \cdot 4 \mathrm{H}_{2} \mathrm{O}$ (99\%, Fluka), and $\mathrm{CaCl}_{2} \cdot 2 \mathrm{H}_{2} \mathrm{O}(99.5 \%$, Fluka) were used without further purification and added directly to the buffer for the molecular recognition studies.

For antimicrobial experiments, American Type Culture Collection (ATCC) Gram-positive bacterial strains Staphylococcus aureus (S. aureus, ATCC® 29213) and staphylococcus coagulase-negative Staphylococcus epidermidis (S. epidermidis, ATCC® 12221 ) and yeast Candida parapsilosis (C. parapsilosis, ATCC® 22109) were purchased from Oxoid ${ }^{\mathrm{TM}}$. Phosphate buffered saline powder (PBS, $\mathrm{pH}=7.4$, Sigma-Aldrich) and Columbia agar plates with $5 \%$ of sheep blood (Bio-Rad) were utilized for suspension and microbial growth, respectively. Mueller Hinton E agar plates from Biomerieux and cation-adjusted BBL Mueller Hinton ( $\mathrm{MH}$ ) broth from Becton, Dickinson and Company were used for leaching and fixative experiments, respectively. The fixing of bacteria onto the polymeric films for SEM experiments was performed with $10 \%$ formalin solution in PBS purchased from Sigma-Aldrich.

\section{Measurements}

Monomer conversion was determined gravimetrically. The zeta potential, average hydrodynamic diameter and particle size distributions were determined by dynamic light scattering using a Malvern Zetasizer Nano ZS instrument at $25{ }^{\circ} \mathrm{C}$. Malvern dispersion software was used for data acquisition and analysis, applying the general purpose algorithm for the determination of the particle size distribution.

Molecular weight distributions were determined by size exclusion chromatography (SEC) using a Waters SEC equipped with a Waters model 510 pump, a 410 differential refractometer and two mixed bead columns (Mixed-C, Polymer Laboratories, $30 \mathrm{~cm}, 40{ }^{\circ} \mathrm{C}$ ) as the separating system. Tetrahydrofuran was employed as an eluent at a flow rate of $1 \mathrm{~mL} \mathrm{~min}^{-1}$ and the equipment was calibrated using narrow molecular weight polystyrene standards $\left(580-7.5 \times 10^{6} \mathrm{~g} \mathrm{~mol}^{-1}\right)$.

Micelles were imaged using transmission electron microscopy (TEM) on a LEO 910 operating at $120 \mathrm{kV}$. Scanning electron microscopy (SEM) images of latex particles, previously coated with gold, were taken using a JEOL JSM-5600 with an acceleration voltage of $10 \mathrm{kV}$. SEM micrographs of bacteria on the films were recorded on a field emission scanning electron microscope (FE-SEM) Hitachi SU 8000 at $30 \mathrm{kV}$. Surface topography of the prepared films from latexes was determined by atomic force microscopy (AFM) on a Multimode Nanoscope IVa, Digital Instrument/Veeco operated in tapping mode under ambient conditions.

Fluorescence spectra of Con A protein interactions were recorded on a Perkin-Elmer LS50B spectrophotometer using an excitation wavelength of $495 \mathrm{~nm}$ and by adjusting emission 
splits as required for the intensity measurements. A fluorescence microscope (Nikon eclipse TE2000-S) was used to study the interaction of the lectin Con A-FITC with the films containing the antimicrobial polymers. The images were captured with a Nikon Digital Sight DS-2MV camera at a fixed exposure time.

\section{Methods}

\section{Synthesis of the polymeric surfactants}

Polymers were previously prepared by atom transfer radical polymerization (ATRP). ${ }^{18}$ Briefly, two macroinitiators of BMA with different degrees of polymerization $\left(\mathrm{PBMA}_{70}-\mathrm{Br}\right.$ and PBMA $_{132}-\mathrm{Br}$ ) were synthesized by ATRP using ethyl 2-bromoisobutyrate (EBrIB) as the initiator and copper(I) bromide $/ N, N, N^{\prime}$, $N^{\prime \prime}, N^{\prime \prime}$-pentamethyldiethylenetriamine (CuBr/PMDETA) as the catalytic system. Subsequently, 2-(dimethylaminoethyl) methacrylate (DMAEMA) and 2-(D-glucosamin-2- $N$-yl)carbonylethyl methacrylate (HEMAGl) monomers were statistically copolymerized from BMA macroinitiators at different feed molar ratios. Finally, complete quaternization of the DMAEMA units to trimethylaminoethyl methacrylate (TMAEMA) units was achieved by reaction with methyl iodide.

\section{Micellar solutions}

Micellar solutions of the synthesized surfactants were prepared by the self-organized precipitation method (SORP). ${ }^{19}$ Polymers were dissolved in a minimal amount of DMF and then deionized water was added dropwise under vigorous stirring until a final volume ratio for the aqueous/organic phase of 4/1 was reached. Subsequently solutions were transferred to a dialysis tube $\left(M_{\mathrm{WCO}}=3.5 \mathrm{kDa}\right)$ and dialyzed against deionized water for DMF removal. The concentrations of the micellar solutions were adjusted to $3 \mathrm{mg} \mathrm{mL} \mathrm{m}^{-1}$ by adding deionized water. These solutions were subsequently analyzed by DLS and used as stock solutions for the emulsion polymerization. TEM images from micelles were obtained after dropping the solution on carbon-coated copper grids.

\section{Emulsion polymerizations of BMA}

Emulsion polymerizations were carried out in batch in a threeneck double-walled reactor provided with a condenser, a nitrogen inlet/outlet and a mechanical three-blade glass stirrer. Following a general procedure, $30 \mathrm{~mL}$ of the corresponding micellar solution $\left(3 \mathrm{mg} \mathrm{mL} \mathrm{m}^{-1}\right)$ were placed in the reactor. Under continuous stirring at $600 \mathrm{rpm}, 1.2$ or $3.0 \mathrm{~g}$ of BMA were added to perform emulsion polymerizations at $4 \%$ and $10 \%$ in solid content, respectively. In a vial, $0.8 \mathrm{wt} \%$ of $\mathrm{V}-50$ initiator (based on the monomer) was dissolved in $1 \mathrm{~mL}$ of deionized water and deoxygenated prior to use. The system was purged with nitrogen for 30 minutes before heating to $70^{\circ} \mathrm{C}$. Once the reaction temperature of $70{ }^{\circ} \mathrm{C}$ was reached, the polymerization was started by the addition of the initiator solution. Samples were taken at regular intervals for 90 minutes and quenched with a certain small amount of hydroquinone. For kinetic studies, monomer conversion was determined gravimetrically and $20 \mu \mathrm{L}$ from each sample were diluted with deionized water or THF for DLS and SEC measurements, respectively. In addition, SEM micrographs were taken from the final latexes.

For comparative purposes, BMA emulsion polymerizations were performed under surfactant-free conditions and using SDS as a surfactant $\left(3 \mathrm{mg} \mathrm{mL} \mathrm{m}^{-1}\right)$ following the same general experimental procedure.

\section{Film formation from the functional latexes}

Films for surface characterization were prepared by casting on glass discs. From each latex, $100 \mu \mathrm{L}$ were cast on the support and water was slowly evaporated for 24 hours at room temperature. Samples were then annealed in an oven at $80^{\circ} \mathrm{C}$ for another 72 hours. The topography of the surface was studied by AFM and the interactions with the glucose-specific binding protein Con A were evaluated by the immersion of films in a solution of the fluorescent protein $\left(0.5 \mathrm{mg} \mathrm{mL}^{-1}\right.$ in a buffer containing $1 \mathrm{mM}$ of $\mathrm{MnCl}_{2}, 1 \mathrm{mM}$ of $\mathrm{CaCl}_{2}$ and $0.5 \mathrm{M}$ of $\mathrm{NaCl}$ ) for 1 hour. The solution was then recovered and the residual fluorescence was compared with the initial fluorescence to quantify the protein retention by the films. In addition, the specific and non-specific protein adsorptions of the films were evaluated directly at the surface. Films were first immersed in a solution of $5 \mathrm{mg} \mathrm{mL} \mathrm{m}^{-1}$ of BSA for $2 \mathrm{~h}$ and subsequently immersed in a $0.5 \mathrm{mg} \mathrm{mL} \mathrm{mL}^{-1}$ of Con A-FITC solution for $1 \mathrm{~h}$ and then the films were measured by fluorescence microscopy.

For antimicrobial studies, films were prepared by casting onto plastic weighing boats $(31 \mathrm{~mm} \times 54 \mathrm{~mm})$ and complete evaporation. Finally, circular pieces of $2 \mathrm{~cm}$ diameter were carefully cut by punching to avoid film cracking.

\section{Evaluation of antimicrobial activity of the films}

Antimicrobial activity was determined following the E2149-01 standard method of the American Society for Testing and Materials (ASTM). ${ }^{20}$ The antimicrobial activity of films was tested against $S$. aureus, $S$. epidermidis and $C$. parapsilosis following the described method but with slight modifications. All microbial strains were initially grown on 5\% sheep blood Columbia agar plates, dispersed, and adjusted with sterile saline solution to a turbidity equivalent to 0.8 McFarland standard $\left(10^{8}\right.$ colony-forming units per $\left.\mathrm{mL}, \mathrm{CFU} \mathrm{mL}^{-1}\right)$. A 200 -fold dilution with phosphate buffered saline then provides the

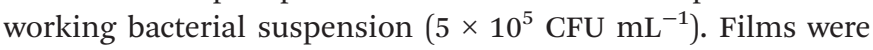
sterilized just before the experiments by washing with ethanol and exposure to UV radiation for 30 minutes. Each sample was placed in a sterile falcon tube and $10 \mathrm{~mL}$ of inoculum with $5 \times 10^{5} \mathrm{CFU} \mathrm{mL}{ }^{-1}$ were then added. Falcon tubes with only the inoculum and with the surfactant-free film were also prepared as control samples. All samples were shaken at $150 \mathrm{rpm}$ for 24 hours at room temperature. Bacterial concentrations at time 0 and after 24 hours were calculated by the plate count method performing 1:10 serial dilutions, followed by the drop plate technique. ${ }^{21}$ Two films of each sample were tested and one of them was plated in duplicate. The reduction in CFU $\mathrm{mL}^{-1}$ was estimated from the average of the results. 


\section{Leaching studies}

The diffusion of the antimicrobial agent from the films to the medium was evaluated. Two different tests were performed, both consisting of the presence or the absence of zones of inhibition around the sample when they are placed on agar plates inoculated with $S$. aureus by the spread plate method and after incubation for $24 \mathrm{~h}$ at $37^{\circ} \mathrm{C}$. A test was done by direct contact of films (1 cm in diameter) face down on the agar plate. In the second test, films immersed in PBS were agitated at $150 \mathrm{rpm}$ for $24 \mathrm{~h}$ and then $100 \mu \mathrm{L}$ of the supernatant were placed in $8 \mathrm{~mm}$ hole bored agar plates.

\section{Bacterial fixation on the films for SEM measurements}

Films were statically incubated in $S$. epidermidis solution $\left(5 \times 10^{5} \mathrm{CFU} \mathrm{mL} \mathrm{m}^{-1}\right.$ prepared as described above, but now in $\mathrm{MH}$ broth) for 90 minutes, time sufficient for bacterial adhesion to take place. The bacterial suspension was then removed and films were covered with fresh $\mathrm{MH}$ broth and incubated for 24 hours at $37^{\circ} \mathrm{C}$. After this incubation period, the films were carefully rinsed several times with PBS, fixed with $10 \%$ formalin solution for 60 minutes at room temperature, washed twice with PBS and water and finally dried for 10 minutes with ethanol/water mixtures increasing sequentially the ethanol content from 30 to 50,70 and $100 \%$.

\section{Results and discussion}

\section{Polymeric surfactants and their self-assembly in aqueous medium}

It is well-known that amphiphilic blocks have been used successfully as stabilizers in emulsion polymerization. Of special interest to the current study are amphiphilic polymers containing quaternary ammonium groups, which have been described extensively as adequate stabilizers, ${ }^{22-24}$ and have been demonstrated to exhibit a high antimicrobial activity. ${ }^{1,8,25-30}$ As mentioned, in our previous work, block copolymers containing hydrophobic segments of poly(butyl methacrylate) (PBMA) and as a hydrophilic block quaternized poly(2-(dimethylamino) ethyl methacrylate), PTMAEMA, statistically modified with HEMAGl glycomonomer units, were synthesized with the purpose of reducing the cytotoxicity of these antimicrobial polymers. ${ }^{18}$ The compositions of these copolymers, used as polymeric surfactants in the current study, are summarized in Table 1.

Generally, self-organization in micelles of amphiphilic surfactants in water is favored by the SORP method. ${ }^{19}$ DLS analysis of aqueous block copolymer solutions confirmed the formation of micellar assemblies with hydrodynamic diameters in the range of $20-50 \mathrm{~nm}$ and also large aggregates with diameters between 100 and $200 \mathrm{~nm}$ (see Fig. 1A). These larger

Table 1 Composition of the antimicrobial block copolymer surfactants used

\begin{tabular}{|c|c|c|c|c|}
\hline & Polymer & $\begin{array}{l}\text { TMAEMA/ } \\
\text { HEMAGl }^{a}\end{array}$ & $\chi_{\text {hydrophobic }}{ }^{b}$ & $\chi_{\text {hydrophilic }}^{b}$ \\
\hline BT & PBMA $_{70}-b$-PTMAEMA 65 & $1 / 0$ & 0.42 & 0.58 \\
\hline S1 & PBMA $_{70}-b-\mathrm{P}\left(\mathrm{TMAEMA}_{0.18}-c o-\mathrm{HEMAGl}_{0.82}\right)_{89}$ & $1 / 5$ & 0.26 & 0.74 \\
\hline $\mathrm{S} 2$ & PBMA $_{70}-b-\mathrm{P}\left(\mathrm{TMAEMA}_{0.53}-c o-\mathrm{HEMAGl}_{0.47}\right)_{234}$ & $1 / 1$ & 0.19 & 0.81 \\
\hline S3 & PBMA $_{70}-b-\mathrm{P}\left(\mathrm{TMAEMA}_{0.68}-c 0-\mathrm{HEMAGl}_{0.32}\right)_{263}$ & $1 / 0.5$ & 0.13 & 0.87 \\
\hline $\mathrm{S} 4$ & PBMA $_{132}-b-\mathrm{P}\left(\mathrm{TMAEMA}_{0.38^{-}}-\mathrm{Co} \mathrm{HEMAGl}_{0.62}\right)_{117}$ & $1 / 1.6$ & 0.36 & 0.64 \\
\hline S5 & PBMA $_{132}-b-\mathrm{P}\left(\mathrm{TMAEMA}_{0.63}-\mathrm{co}-\mathrm{HEMAGl}_{0.37}\right)_{224}$ & $1 / 0.6$ & 0.25 & 0.75 \\
\hline S6 & $\mathrm{PBMA}_{132}-b-\mathrm{P}\left(\mathrm{TMAEMA}_{0.88^{-}}-\mathrm{Co}-\mathrm{HEMAGl}_{0.12}\right)_{127}$ & $1 / 0.1$ & 0.40 & 0.60 \\
\hline
\end{tabular}

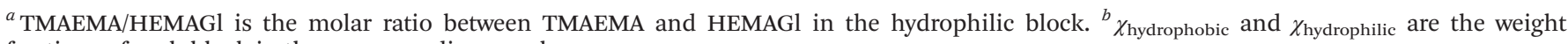
fractions of each block in the corresponding copolymer.
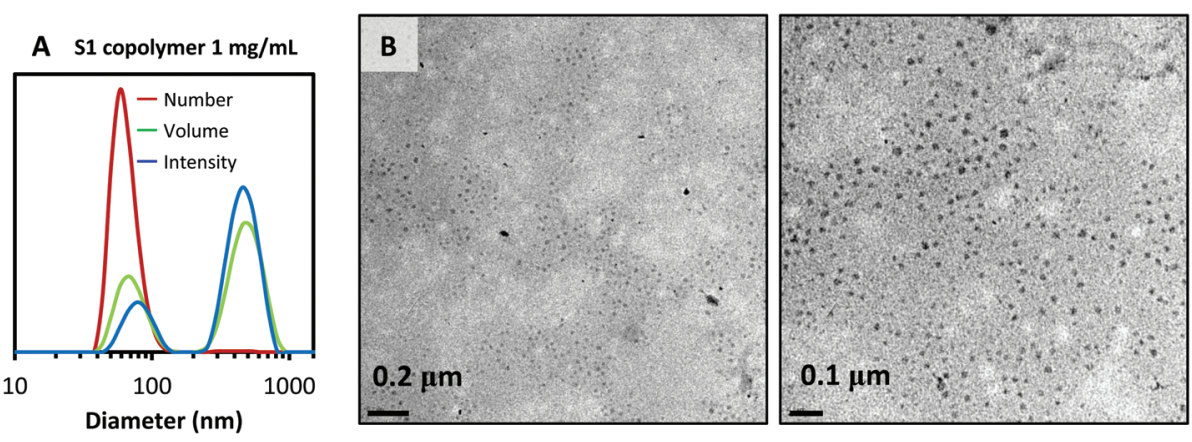

Fig. 1 (A) DLS curves of the S1 copolymer at $1 \mathrm{mg} \mathrm{mL}^{-1}$ in aqueous solution. (B) TEM micrographs of S1 micellar solution (3 mg mL $\mathrm{m}^{-1}$ ) at different magnifications. 
aggregates seemed to be stable as no changes in size were observed when several dilutions were performed. ${ }^{31}$ Furthermore, the critical micelle concentrations (CMC) were not detectable by DLS in any of the copolymer systems, even at the lowest measurable concentrations by the instrument. Therefore, the working block copolymer concentrations in the emulsion polymerizations as described below are all well above the CMC. TEM micrographs confirm the formation of micelles and help to clarify the morphology and size of these waterorganized structures. As can be seen in the micrograph taken from micellar solution of surfactant S1 (Fig. 1B), micelles around $20 \mathrm{~nm}$ and some larger aggregates were observed confirming the DLS results.

\section{Emulsion polymerizations}

Emulsion polymerization reactions of the BMA monomer were carried out in batch at $4 \%$ and $10 \%$ solid content. In all experiments, the absolute amount of the surfactant was maintained constant (90 mg); this corresponds to 7.5 and $3.0 \mathrm{wt} \%$ (based on the monomer) for $4 \%$ and $10 \%$ solid content, respectively. The concentration of the initiator was fixed at $0.8 \mathrm{wt} \%$ in both cases and the polymerizations were left to proceed for a total of 90 minutes.

The kinetics of the emulsion polymerizations were studied by following the progress of the conversion during the reactions as displayed in Fig. 2. It should be noted here that except for the polymerizations using $\mathrm{S} 1$ and $\mathrm{S} 2$ at $4 \%$ solids and S1, $\mathrm{S} 2$ and $\mathrm{S} 3$ at $10 \%$ solids all polymerizations go to full monomer conversions, and that the apparent limiting conversions in some of the runs are due to some evaporation of the monomer during polymerization.

When comparing the results of Fig. 2, two observations were immediately made: (i) the polymerizations at $4 \%$ solid content are slightly faster than those at $10 \%$ solid content, and (ii) that the results clearly depend on the type of block copolymer used. Furthermore, the rates of the block copolymer stabilized systems are all lower than those of the SDS-stabilized systems (with polymerization rates and particle numbers similar to those reported in the literature ${ }^{32}$ ) and faster than the surfactant-free systems, as expected. Polymerization rates for all the emulsion reactions are summarized in Table 2.

The difference in polymerization rates between the $4 \%$ solid content polymerizations and those at $10 \%$ solid content may be due to the fact that in the latter case more surfactant is required to stabilize the monomer droplets, which effectively reduces the number of micelles available to polymerization which in turn reduces the particle number $\left(N_{\mathrm{P}}\right)$. Since the rate of polymerization $\left(R_{\mathrm{P}}\right)$ is directly proportional to the particle number $\left(R_{\mathrm{p}} \propto N_{\mathrm{P}}\right)$ this would lead to higher rates for the $4 \%$ solid polymerizations. The numbers of particles per $\mathrm{dm}^{3}$ of water can be estimated from the average particle diameters, which we measured by DLS, using eqn (1) where $M_{\mathrm{o}}(\mathrm{g})$ is the initial amount of the monomer, $X_{\mathrm{F}}$ is the final conversion, $\rho_{\mathrm{P}}$ $\left(\mathrm{g} \mathrm{cm}^{-3}\right)$ is the density of PBMA $\left(\rho=1.07 \mathrm{~g} \mathrm{~cm}^{-3}\right), \rho_{\mathrm{W}}\left(\mathrm{g} \mathrm{cm}^{-3}\right)$ is the density of water, $D(\mathrm{~nm})$ is the diameter of the final latex particles and $W_{\mathrm{H}_{2} \mathrm{O}}(\mathrm{g})$ is the weight of water. ${ }^{32}$

$$
N_{\mathrm{P}} / \mathrm{dm}^{3}=\frac{M_{\mathrm{O}} X_{\mathrm{F}} \rho_{\mathrm{W}} 6 \times 10^{24}}{\rho_{\mathrm{P}} \pi D^{3} W_{\mathrm{H}_{2} \mathrm{O}}}
$$

Derived particle numbers and average particle diameters for all our experiments are listed in Tables 2 and 3, respectively. When comparing the results for S4-S6 (i.e., the runs without coagulum formation) we indeed observe (slightly) higher particle numbers at $4 \%$ solid content. The results for SDS and BT deviate in this respect, which suggests different dynamics for these systems.

The results in Table 3 also show very similar positive $\zeta$-potentials for the surfactant-free and the block copolymer stabilized latexes. The surfactant free latex presents surface charges because the V50 initiator provides amidine groups able to be protonated giving positive charges at the surfaces. ${ }^{33}$
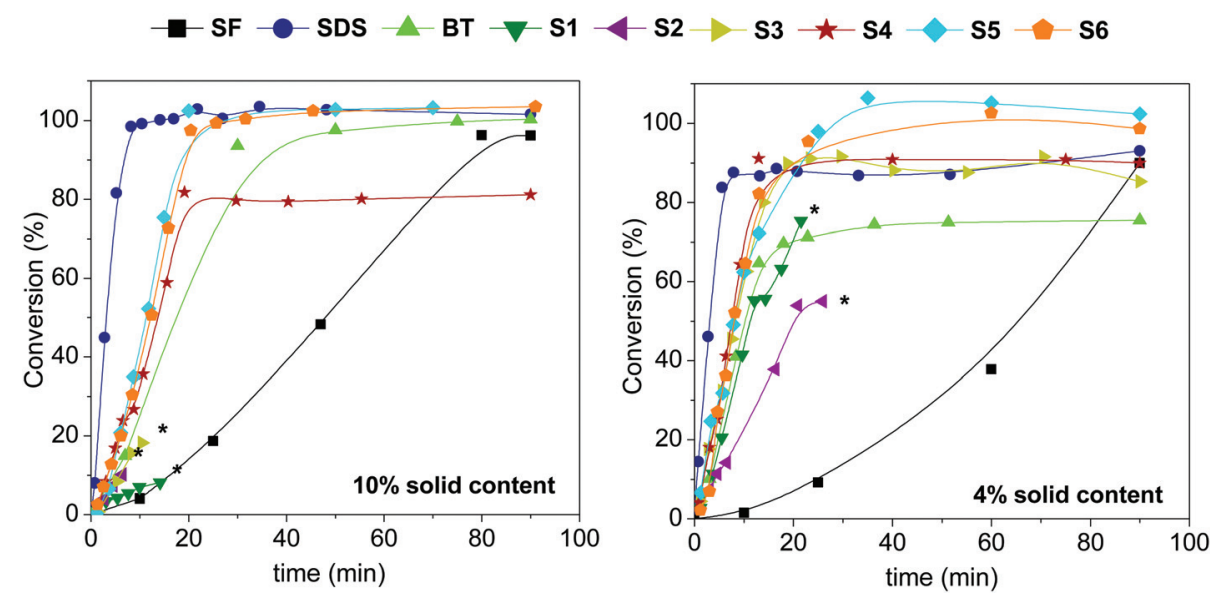

Fig. 2 Monomer conversion versus time of emulsion polymerizations of BMA at 10\% (left) and 4\% (right) solid content for a range of different surfactants. SF: surfactant-free. (*) Point at which the coagulum starts to appear. 
Table 2 Rate of polymerization $\left(R_{\mathrm{P}}\right)$, number of particles $\left(N_{\mathrm{P}}\right)$ and rate of polymerization per particle $\left(R_{\mathrm{PP}}\right)$ for the final latexes

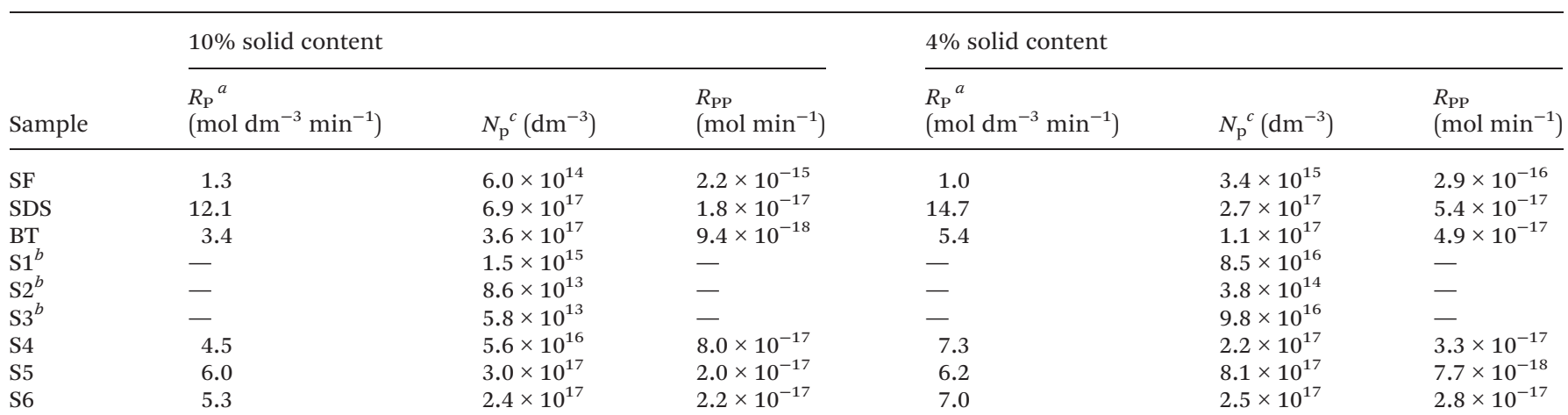

${ }^{a} \mathrm{R}_{\mathrm{P}}$ obtained from the linear part of the conversion curves (interval II). ${ }^{b}$ The data reported for the latexes prepared with surfactants $\mathrm{S} 1$, S2 and S3 refer to the stable latexes after removal of the coagulum. ${ }^{c} \mathrm{NP}$ is the particle number calculated from eqn (1).

Table 3 Parameters of the final latexes obtained from emulsion polymerizations of $\mathrm{BMA}$ at $10 \%$ and $4 \%$ solid content

\begin{tabular}{|c|c|c|c|c|c|c|c|c|}
\hline \multirow[b]{2}{*}{ Sample } & \multicolumn{4}{|c|}{$10 \%$ solid content } & \multicolumn{4}{|c|}{$4 \%$ solid content } \\
\hline & $\begin{array}{l}D_{\mathrm{n}}{ }^{a} \\
(\mathrm{~nm})\end{array}$ & PdI $^{b}$ & $\begin{array}{l}C^{c} \\
(\%)\end{array}$ & $\begin{array}{l}\zeta^{d} \\
(\mathrm{mV})\end{array}$ & $\begin{array}{l}D_{\mathrm{n}}{ }^{a} \\
(\mathrm{~nm})\end{array}$ & PdI $^{b}$ & $\begin{array}{l}C^{c} \\
(\%)\end{array}$ & $\begin{array}{l}\zeta^{d} \\
(\mathrm{mV})\end{array}$ \\
\hline $\mathrm{SF}$ & 637 & 0.06 & 0 & 52 & 263 & 0.03 & 0 & 46 \\
\hline SDS & 63 & 0.04 & 0 & -42 & 61 & 0.03 & 0 & -43 \\
\hline BT & 78 & 0.19 & 0 & 67 & 76 & 0.09 & 0 & 52 \\
\hline $\mathrm{S} 1^{e}$ & 385 & 0.20 & 40 & 53 & 83 & 0.18 & 10 & 49 \\
\hline $\mathrm{S} 2^{e}$ & 965 & 0.12 & 90 & 60 & 464 & 0.81 & 50 & 58 \\
\hline $\mathrm{S} 3^{e}$ & 965 & 0.11 & 100 & 48 & 86 & 0.56 & 0 & 55 \\
\hline S4 & 135 & 0.05 & 0 & 47 & 66 & 0.05 & 0 & 46 \\
\hline S5 & 83 & 0.05 & 0 & 54 & 44 & 0.07 & 0 & 54 \\
\hline S6 & 90 & 0.04 & 0 & 50 & 65 & 0.07 & 0 & 51 \\
\hline
\end{tabular}

${ }^{a} D_{\mathrm{n}}$ is the number-average particle diameter. ${ }^{b} \mathrm{PdI}$ is the latex polydispersity. ${ }^{c} C(\%)$ is the weight percentage of the coagulated latex at total conversion. ${ }^{d} \zeta$ is the zeta potential of particles. ${ }^{e}$ The data reported for the latexes prepared with surfactants S1, S2 and S3 refer to the stable latexes after removal of the coagulum.

Only the latexes stabilized by the negatively charged SDS have a negative $\zeta$-potential as expected.

Returning now to the results in Fig. 2, it is clear that not all the used surfactants are capable of producing stable latexes. As can be seen in the conversion plots, the surfactants BT, S4, S5 and S6 perform well under all the investigated conditions. Polymerizations performed with $10 \%$ solid contents and surfactants S1, S2 and S3 (copolymers with a hydrophobic block length of 70 units and with hydrophilic contents ranging from $74 \%$ to $87 \%$ ), however, resulted in coagulum formation at low conversions. In the case of the most hydrophilic surfactant S3, the coagulum content even reached $100 \%$ at the end of the polymerization. Decreasing the solid content from $10 \%$ to $4 \%$ improved the stabilization greatly. Coagulum formation was reduced from $40 \%$ to $10 \%$ in the $\mathrm{S} 1$ system, from $90 \%$ to $50 \%$ in the S2 system and from $100 \%$ to $0 \%$ in the S3 system.

From these results it is safe to conclude that copolymer composition and behavior in emulsion polymerization are directly related. The results suggest that using copolymers with too high hydrophilic fractions and higher HEMAGl contents in the statistical block result in unstable latexes. An optimal stabilization requires a certain hydrophilic/hydrophobic balance $^{34}$ in the copolymer composition and although, in general terms, a longer hydrophilic fraction is necessary to stabilize oil-in-water emulsions, the surface-active properties can be lost with an excess of hydrophilicity. ${ }^{35}$ This is the case of S2 and S3 copolymers with hydrophilic fractions of 0.8 and 0.9 , respectively. A second factor to be taken into account is the glycomonomer unit. Glycopolymers are known to be poor surfactants by themselves ${ }^{14,15}$ and, sometimes, the addition of a co-surfactant is required. ${ }^{36,37}$ Although the presence of the positively charged TMAEMA units should improve the surfactant properties, TMAEMA contents below 20\%, as in the S1 copolymer, do not seem to be enough for efficiently stabilizing higher solid contents in emulsion polymerizations.

The different abilities of these copolymers to act as stabilizers in emulsion polymerization are also reflected in the final particle diameters and distributions. As can be seen from the data in Table 3, the latexes resulting from the better block copolymer surfactants BT, S4, S5 and S6 have small particle diameters and narrow distributions. The latexes (after removal of the coagulum) prepared using S1, S2 and S3 are characterized by larger particles (with diameters of around $1 \mu \mathrm{m}$ for S2 and S3) and broad distributions. These results were further confirmed by SEM measurements of the final latexes (see Fig. 3).

These SEM micrographs clearly show differences in the particle size distributions obtained using good (BT, S4-S6) and poor (S1-S3) surfactants. Whereas a uniform, monomodal distribution of spherical particles is obtained in the former case, the images for S1-S3 show less spherical particles and especially for S2 and S3 a multimodal distribution. The irregular shapes of the larger particles strongly suggest that primary particles coalesced during the polymerization. That this is indeed what happened during these polymerizations is supported by the molecular weight data of the resulting polymers which are listed in Table 4. Leaving the SDS data out of 


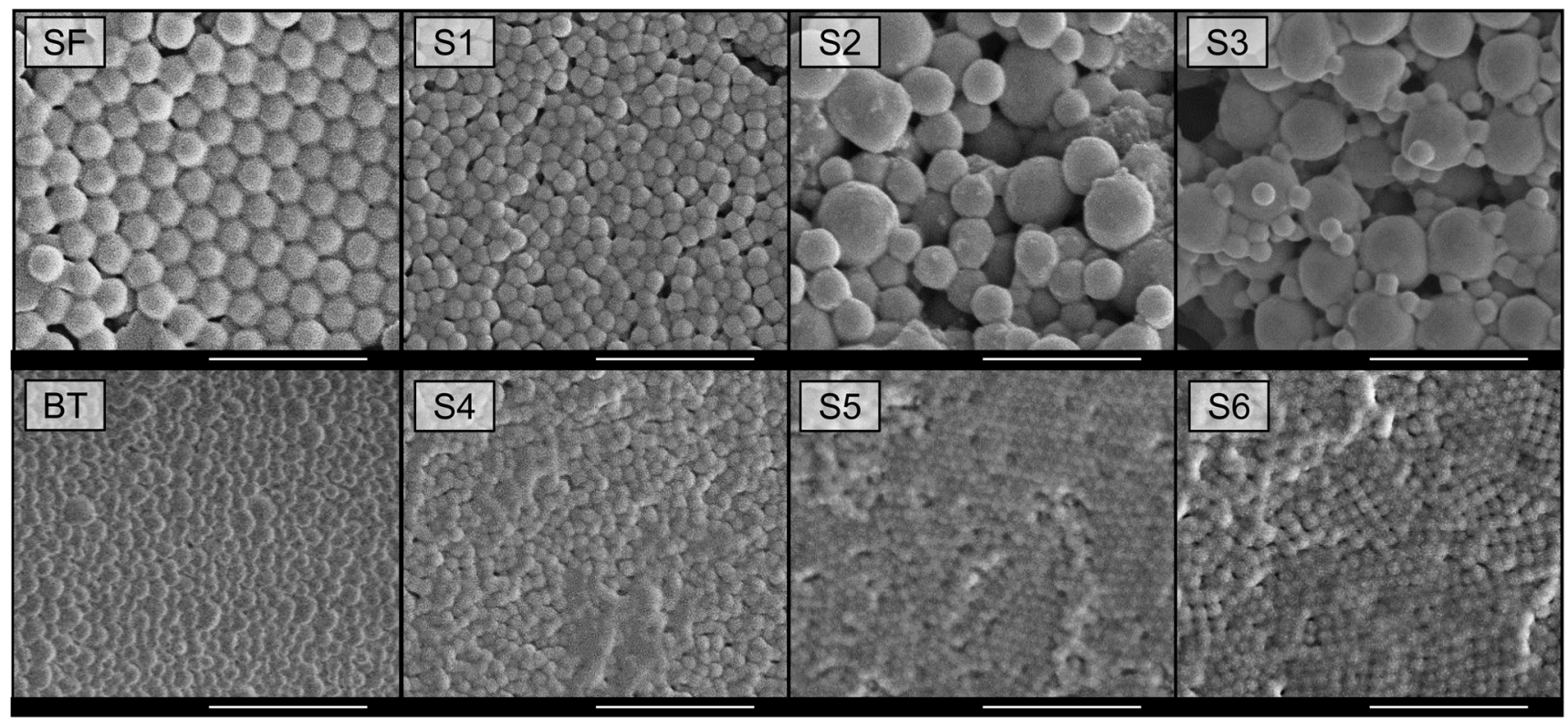

Fig. 3 SEM micrographs of final latex particles at $4 \%$ solid content. Scale bar: $1 \mu \mathrm{m}$.

Table 4 Average molecular weights and polydispersities of the final latexes obtained by SEC

\begin{tabular}{|c|c|c|c|c|c|c|}
\hline \multirow[b]{2}{*}{ Sample } & \multicolumn{2}{|c|}{$\begin{array}{l}M_{\mathrm{n}} \times 10^{-5} \\
\left(\mathrm{~g} \mathrm{~mol}^{-1}\right)\end{array}$} & \multicolumn{2}{|c|}{$\begin{array}{l}M_{\mathrm{W}} \times 10^{-5} \\
\left.(\mathrm{~g} \mathrm{~mol})^{-1}\right)\end{array}$} & \multicolumn{2}{|l|}{ PdI } \\
\hline & $10 \%$ & $4 \%$ & $10 \%$ & $4 \%$ & $10 \%$ & $4 \%$ \\
\hline SF & 1.4 & 2.2 & 3.8 & 6.1 & 2.6 & 2.7 \\
\hline SDS & 12.7 & 12.0 & 24.7 & 24.3 & 1.9 & 2.0 \\
\hline BT & 2.7 & 3.1 & 5.2 & 7.0 & 1.9 & 2.2 \\
\hline S1 & 3.2 & 3.9 & 6.6 & 8.2 & 2.0 & 2.1 \\
\hline S2 & 1.9 & 2.5 & 4.8 & 7.5 & 2.5 & 2.9 \\
\hline S3 & 3.6 & 4.8 & 9.6 & 10.4 & 2.6 & 2.1 \\
\hline S4 & 4.2 & 5.4 & 8.9 & 10.5 & 2.1 & 1.9 \\
\hline S5 & 5.0 & 6.1 & 7.8 & 12.8 & 1.9 & 2.0 \\
\hline S6 & 4.3 & 5.5 & 8.4 & 10.4 & 1.9 & 1.8 \\
\hline
\end{tabular}

consideration, it can be seen that the molecular weights of the polymers obtained in all block copolymer-stabilized emulsion polymerizations are very similar, suggesting very similar (primary) particle numbers $\left(M_{\mathrm{n}} \propto N_{\mathrm{P}}\right)$.

There is also a small difference between the data at $4 \%$ and $10 \%$ solids, with the molecular weights obtained at $4 \%$ being slightly larger. Although this may be due to the larger particle numbers at $4 \%$ (see Table 2), this may also be due to the difference in initiator concentration $\left(M_{\mathrm{n}} \propto[\mathrm{I}]^{-1}\right)$. Finally, polydispersities of around 2 are obtained in all the cases. These values are expected in emulsion polymerization based on the compartmentalization of propagating radicals. Compared to bulk polymerizations, it is known that molecular weight distributions for bimolecular termination are broader while distributions due to chain transfer terminations are not affected by the emulsion polymerization. ${ }^{38}$ Methacrylates largely terminate via disproportionation and it has been shown that BMA suffer from chain transfer to monomers more significantly than other similar monomers described in the literature, thus polydispersity values close to 2 are expected. ${ }^{39}$

\section{Film preparation}

The obtained latexes were subsequently used for the preparation of polymeric films to provide functional surfaces with antimicrobial activity. For this purpose, only stable and clear latexes were utilized; therefore, the latexes obtained with S1, S2 and S3 were disregarded. Films from the surfactant free latexes were prepared and used as blank experiments. To study the process of the film formation, latexes were cast onto glass supports and water was completely evaporated at room temperature $\left(25^{\circ} \mathrm{C}\right)$. The low glass transition temperature of PBMA $\left(\sim 20{ }^{\circ} \mathrm{C}\right)$ favors film formation of this material even at room temperature. However, since surfactants present on the particle interface can be an impediment for the diffusion of PBMA chains and particle coalescence, ${ }^{40}$ an annealing process at $80{ }^{\circ} \mathrm{C}$ was applied to the room temperature-casted films. Changes in their topography were registered by AFM and are shown in Fig. 4. It is clear from these results that the distinct spheres that are present before annealing (upper images in Fig. 4) have disappeared after annealing (lower images in Fig. 4) and that a substantial smoothing of the surface has taken place during the annealing process. Latexes with narrow size distributions are able to organize themselves in more compact structures while the film is forming as can be noted in S4 film images. Particles tend to arrange in a face cubic centered packing. Similar results were also observed for S5 and S6 films (data not shown).

The ultimate aim of this study is to arrive at antimicrobial surfaces and the functionality of the surface is determined by the segregation of surfactant molecules to the film-air inter- 

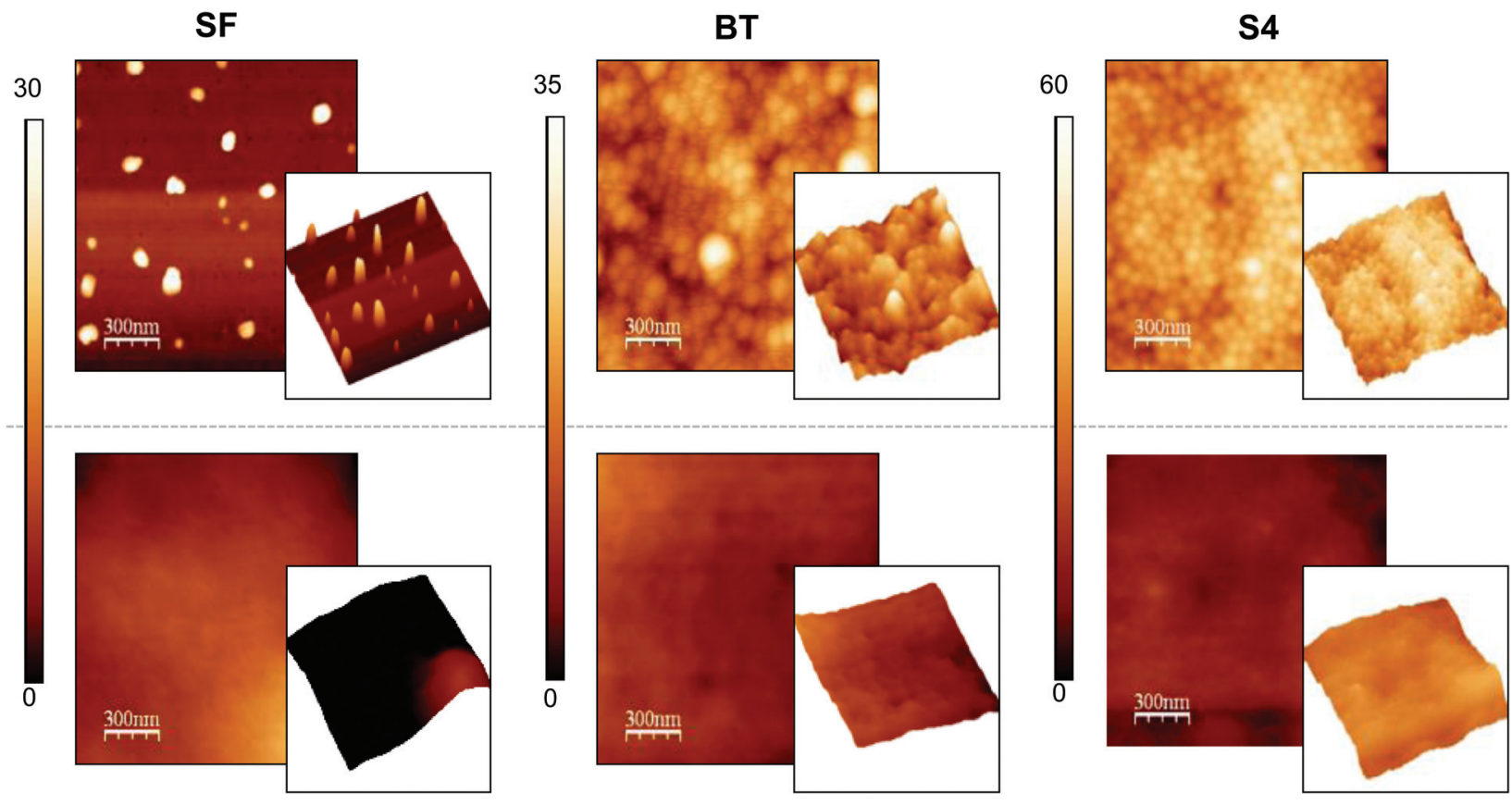

Fig. 4 AFM 2D and 3D topography images of films prepared by casting from SF, BT and S4 latexes (4\% solid content). Upper images correspond to films made at room temperature. Lower images correspond to films annealed at $80^{\circ} \mathrm{C}$. Image size: $1.5 \times 1.5 \mu \mathrm{m}$. Scale bar: $300 \mathrm{~nm}$. Color scale in $\mathrm{nm}$.

face during film formation. Hence the presence of the surfactant on the surface was verified by immersing the films in a solution of fluorescent-labelled Con A (FITC-Con A), which specifically binds to glucose molecules present in the block copolymers. The greater the number of glucose units, the greater the interaction with the protein and the lower the fluorescence intensity that remains in the solution. Fluorescence measurements can then be used to indirectly and qualitatively determine the amount of surfactant present at the surface.

In Fig. 5 are plotted the emission fluorescence spectra of the FITC-Con A solutions. From these spectra it is clear that, after the incubation, the residual fluorescence was much lower for block copolymer-containing films than for the surfactant free film. This implies that greater protein retention occurred on the block copolymer-containing films. Surprisingly, the results in Fig. 5 do not show any significant differences between films prepared from $4 \%$ (dashed lines) or $10 \%$ (continuous lines) solid content latexes. Since the former contain a larger weight fraction of block copolymers, we had expected to see a larger retention for these films. In addition to specific glucose-Con A binding interactions, this greater protein retention on the block copolymer-containing films (especially to BT films, which do not contain HEMAGl units) may be partially due to electrostatic interactions.

To prove this idea, further experiments to test the interaction with specific Con A lectin and non-specific BSA protein were performed. A solution of $5 \mathrm{mg} \mathrm{mL} \mathrm{mL}^{-1}$ of BSA was prepared and films were immersed in it for $2 \mathrm{~h}$ to block the nonspecific adsorptions of proteins. After this period, the films were exposed to $0.5 \mathrm{mg} \mathrm{mL}^{-1}$ of Con A-FITC solution for $1 \mathrm{~h}$ and

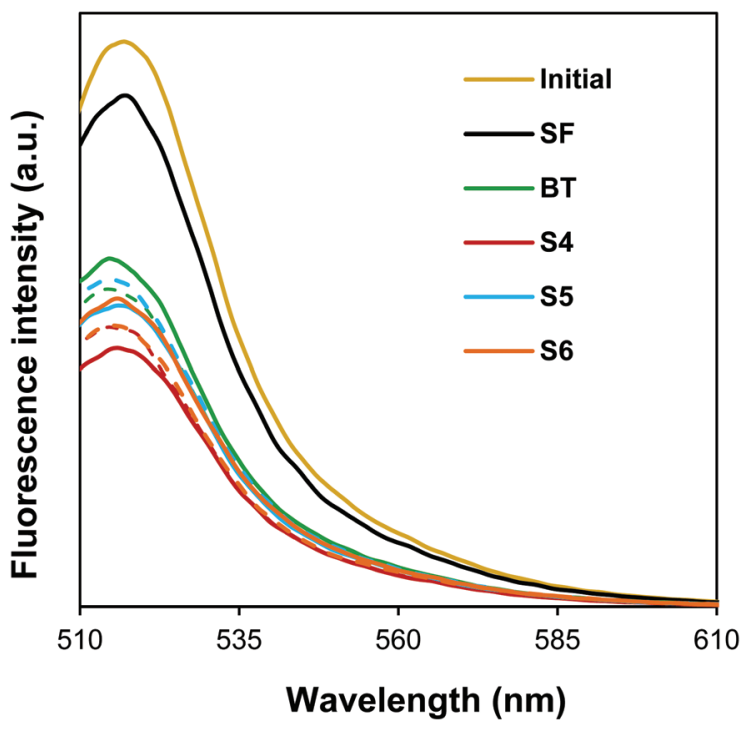

Fig. 5 Fluorescence emission spectra $\left(\lambda_{\text {ex }}=495 \mathrm{~nm}\right)$ of Con A-FITC solution $\left(0.5 \mathrm{mg} \mathrm{mL}^{-1}\right)$ before (initial) and after immersion of the films for 1 hour. Continuous lines: films prepared from 10\% latexes. Dashed lines: films prepared from $4 \%$ latexes.

the fluorescence of the films was measured (Fig. 6). As can be observed, now the BT films do not adsorb lectin, because the electrostatic interactions have been blocked by BSA protein, nor do the SF films. The relative fluorescence values in each film measured throughout gray scale are lower than those previously measured (Fig. 6A and B) as there is no contribution of 


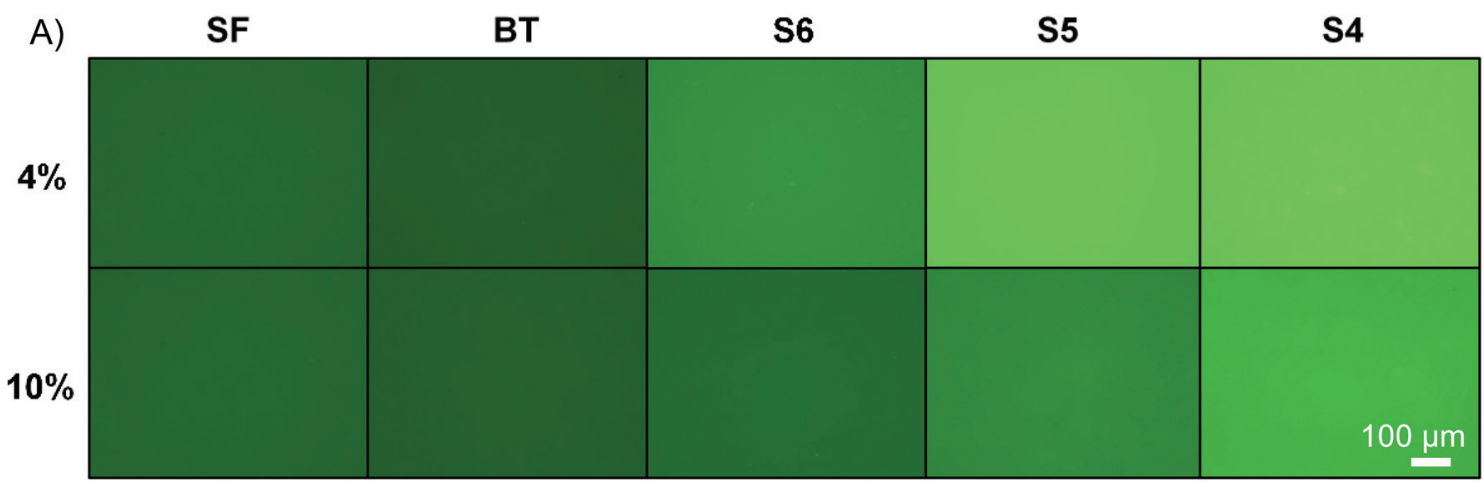

B)

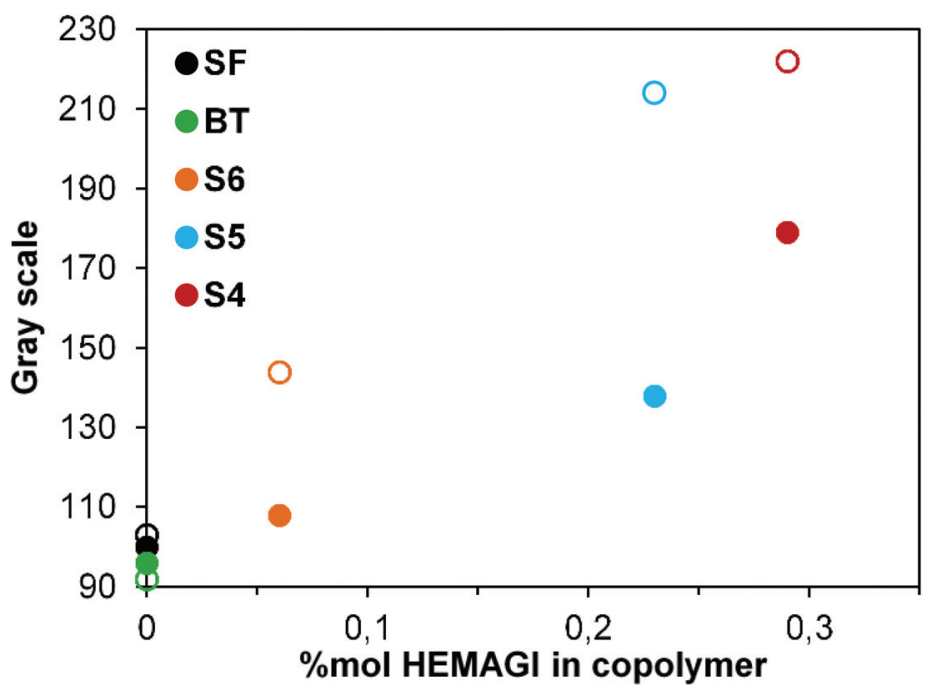

Fig. 6 (A) Fluorescence images taken with a fixed exposure time and (B) gray scale against the glycounit content of the films after immersion with Con A-FITC solution $\left(0.5 \mathrm{mg} \mathrm{mL}^{-1}\right)$ for 1 hour, which were previously exposed to a solution of BSA $\left(5 \mathrm{mg} \mathrm{mL}^{-1}\right)$ for $2 \mathrm{~h}$. Open symbols: films prepared from $4 \%$ latexes. Closed symbols: films prepared from $10 \%$ latexes.

the electrostatic interactions. However, it is clearly observed that there are differences between films prepared from $4 \%$ and $10 \%$ of solid content.

In conclusion we can state that, although some uncontrollable variables such as film roughness or mobility of the copolymers in the blend affect the results and therefore we cannot establish any quantitative correlation, it is clear that the films have surface carbohydrate functionality.

\section{Antimicrobial surfaces}

Antimicrobial activities of these films were evaluated by the socalled shake-flask method (E2149). ${ }^{20}$ This method has been previously used to determine the antimicrobial activity under similar conditions and for similar materials. ${ }^{41}$ This method directly relates the reduction of $\mathrm{CFU} \mathrm{mL}^{-1}$ of microorganism to the antimicrobial properties of a sample after a fixed contact time. Following the method, the reduction is reported in terms of $\log$ reduction value with respect to a control sample composed of the same material but without the antimicrobial agent, i.e., the surfactant-free films. Experiments were performed at room temperature and in PBS as the medium to mimic the environmental conditions using $5 \times 10^{5}$ CFU $\mathrm{mL}^{-1}$ of microorganisms. Results of these experiments using BT and S6 containing films are shown in Table 5, which tabulates the reduction of living bacteria $\left(\log \mathrm{CFU} \mathrm{mL}^{-1}\right)$ after 24 hours for the tested films. Only the results for the BT and S6 containing films are shown because only these films showed a reduction greater than 90\%; S4 and S5 containing films did not show a significant reduction in $\mathrm{CFU} \mathrm{mL}^{-1}$ (below 90\%).

The copolymers that exhibited the higher antimicrobial activity in solution (results reported in a previous publication $)^{18}$ were also the most efficient ones in CFU reduction at the surface of the film. It is also important to note that, in contrast to the protein binding experiments, a large effect of block copolymer content on antimicrobial action is observed. The highest reduction was achieved with films possessing more antimicrobial agent ( $4 \%$ films) reaching or close to $100 \%$ reduction in some cases. Although some bacteria remain on the films after the antimicrobial action, the bacteria could be morphologically affected. This population reduction can be clearly appreciated in SEM micrographs of BT and S6 films compared to the SF blank experiment in Fig. 7. This suggests 
Table 5 Reduction in surviving microorganisms ( $\log \mathrm{CFU} \mathrm{mL} \mathrm{L}^{-1}$ ) after 24 hours

\begin{tabular}{|c|c|c|c|c|c|c|}
\hline \multirow[b]{2}{*}{ Film } & \multicolumn{2}{|c|}{ S. aureus } & \multicolumn{2}{|c|}{ S. epidermidis } & \multicolumn{2}{|c|}{ C. parapsilosis } \\
\hline & $\begin{array}{l}4 \% \\
\text { solids }\end{array}$ & $\begin{array}{l}10 \% \\
\text { solids }\end{array}$ & $\begin{array}{l}4 \% \\
\text { solids }\end{array}$ & $\begin{array}{l}10 \% \\
\text { solids }\end{array}$ & $\begin{array}{l}4 \% \\
\text { solids }\end{array}$ & $\begin{array}{l}10 \% \\
\text { solids }\end{array}$ \\
\hline BT & 5.30 & 0.69 & 5.00 & 1.10 & 2.30 & 1.18 \\
\hline S6 & 2.70 & 0.87 & 1.00 & 0.47 & 2.45 & 1.57 \\
\hline
\end{tabular}

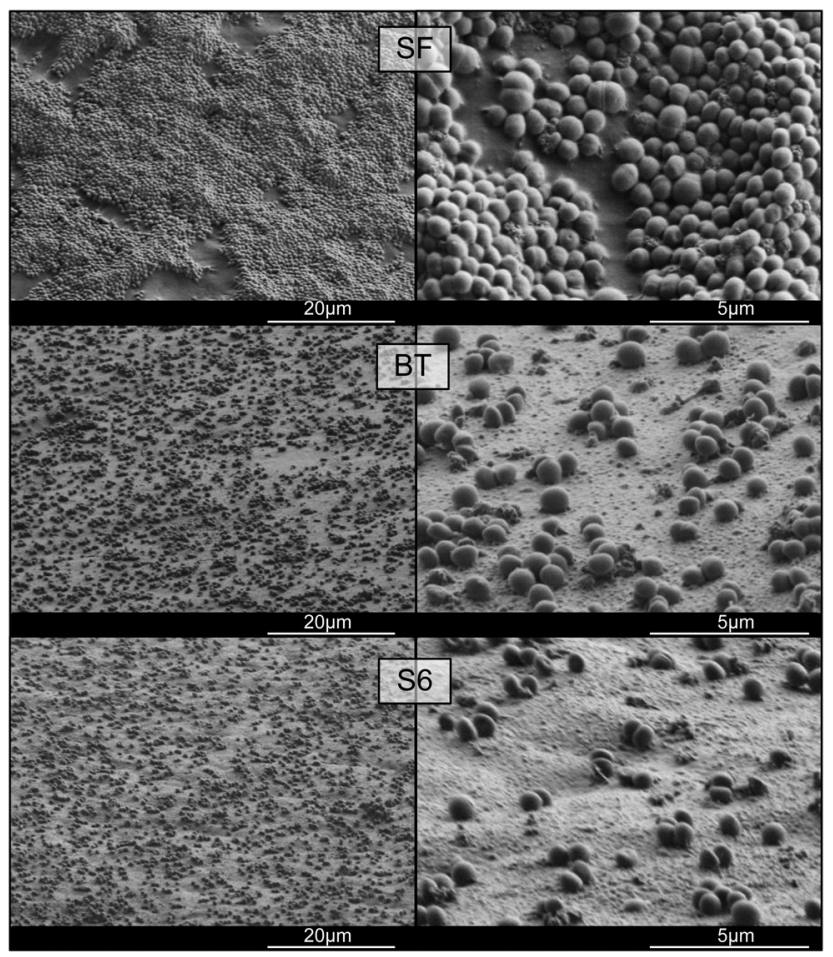

Fig. 7 SEM images of S. epidermidis on $4 \%$ antimicrobial films after $24 \mathrm{~h}$ of contact. Left: 2000x magnification. Right: $10000 x$ magnification.
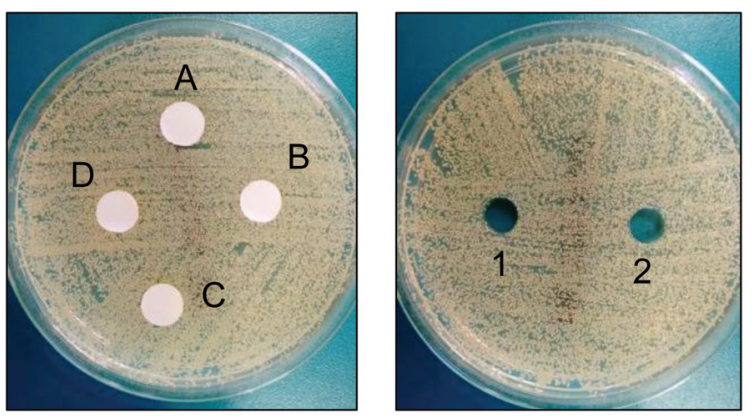

Fig. 8 Surfactant leaching tests. Contact test with the films (left) and test of the supernatant after having the films in the media for $24 \mathrm{~h}$ using S. aureus inoculated MH agar plates (right). Films: SF 10\% (A), BT 10\% (B), BT $4 \%$ (C) and S5 10\% (D) (left) and (1) and (2) the corresponding supernatants of $B$ and $D$ films, respectively (right). that bacteria detach from the surface once they are killed and those on the surface are the surviving bacteria.

In order to discard antimicrobial activity due to surfactant diffusion from films, leaching was examined as described in the Experimental section. Both experiments were negative since no inhibition zone was appreciated directly from films (Fig. 8, left) when the supernatants are poured into the spread agar plate (see Fig. 8, right). Therefore, bacteria are killed in contact mode with the antimicrobial surfaces of the films.

\section{Conclusions}

Antimicrobial coatings of poly(butyl methacrylate) were successfully prepared via the film formation of PBMA latex particles stabilized by antimicrobial block copolymer surfactants. The polymeric surfactants composed of a hydrophobic poly(butyl methacrylate) block and a statistical hydrophilic block based on TMAEMA and HEMAGl glycomonomers were previously synthesized by ATRP at different compositions and lengths. The self-organization properties of these amphiphilic copolymers allowed the formation of micelles and their use as surfactants in the emulsion polymerization of BMA at 4 and $10 \%$ solid content. In general the polymerization results were as expected. Conversions of $100 \%$ were achieved for most of the polymerizations resulting in stable latexes with particle diameters below $100 \mathrm{~nm}$ and narrow polydispersities. The use of copolymer surfactants with high hydrophilicity in addition to a high HEMAGl content did not lead to stable latexes, although the results improved slightly when reducing the solid content from $10 \%$ to $4 \%$. The stable latexes were used for film formation studies and smooth films were formed after annealing at $80^{\circ} \mathrm{C}$ to favor inter-particle diffusion of polymer chains. The presence of functional groups on the surface was confirmed by protein adsorption studies and by the reduction in $\mathrm{CFU} \mathrm{mL} \mathrm{m}^{-1}$ of microorganisms in contact with the films. It was also demonstrated that there was no leaching of surfactants from the films, implying that the antimicrobial activity is retained on the films. In summary, this work presents a straightforward method to obtain durable antimicrobial surfaces.

\section{Acknowledgements}

This work was financially supported by the MINECO (projects MAT2010-17016 and MAT2013-47902-C2-1-R). M. Álvarez-Paino and A. Muñoz-Bonilla also acknowledge the MINECO for financial support of their FPI grant and Ramon y Cajal contract, respectively.

\section{References}

1 A. Muñoz-Bonilla, M. L. Cerrada and M. Fernández-García, Polymeric Materials with Antimicrobial Activity: From Synthesis to Applications, The Royal Society of Chemistry, 2014. 
2 W. J. Yang, K.-G. Neoh, E.-T. Kang, S. L.-M. Teo and D. Rittschof, Prog. Polym. Sci., 2014, 39, 1017-1042.

3 P. Tenke, B. Köves and T. E. B. Johansen, Curr. Opin. Infect. Dis., 2014, 27, 102-107.

4 J. W. Costerton, P. S. Stewart and E. P. Greenberg, Science, 1999, 284, 1318-1322.

5 E. M. Hetrick and M. H. Schoenfisch, Chem. Soc. Rev., 2006, 35, 780-789.

6 A. Muñoz-Bonilla and M. Fernández-García, Eur. Polym. J, 2015, 65, 46-62.

7 K. Glinel, P. Thebault, V. Humblot, C. M. Pradier and T. Jouenne, Acta Biomater., 2012, 8, 1670-1684.

8 A. Muñoz-Bonilla and M. Fernández-García, Prog. Polym. Sci., 2012, 37, 281-339.

9 N. Hadjesfandiari, K. Yu, Y. Mei and J. N. Kizhakkedathu, J. Mater. Chem. B, 2014, 2, 4968-4978.

10 Y. Ye, Q. Song and Y. Mao, J. Mater. Chem., 2011, 21, 13188-13194.

11 J. A. Lichter, K. J. Van Vliet and M. F. Rubner, Macromolecules, 2009, 42, 8573-8586.

12 M. B. Yagci, S. Bolca, J. P. A. Heuts, W. Ming and G. de With, Prog. Org. Coat., 2011, 72, 305-314.

13 M. B. Yagci, S. Bolca, J. P. A. Heuts, W. Ming and G. de With, Prog. Org. Coat., 2011, 72, 343-347.

14 M. Alvárez-Paino, R. Juan-Rodríguez, R. Cuervo-Rodríguez, A. Muñoz-Bonilla and M. Fernández-García, J. Colloid Interface Sci., 2014, 417, 336-345.

15 A. Muñoz-Bonilla, J. P. A. Heuts and M. Fernández-García, Soft Matter, 2011, 7, 2493-2499.

16 A. Muñoz-Bonilla, A. M. Van Herk and J. P. A. Heuts, Macromolecules, 2010, 43, 2721-2731.

17 A. D. Fuchs and J. C. Tiller, Angew. Chem., Int. Ed., 2006, 45, 6759-6762.

18 M. Álvarez-Paino, A. Muñoz-Bonilla, F. López-Fabal, J. L. Gómez-Garcés, J. P. A. Heuts and M. Fernández-García, Biomacromolecules, 2015, 16, 295-303.

19 H. Yabu, Polym. J., 2013, 45, 261-268.

20 ASTM E2149-01, Standard Test Method for Determining the Antimicrobial Activity of Immobilized Antimicrobial Agents Under Dynamic Contact Conditions (Withdrawn 2010), ASTM International, West Conshohocken, PA, 2001, http://www. astm.org.

21 E. Goldman and L. H. Green, Practical Handbook of Microbiology, CRC Press, 2nd edn, 2008.

22 M. Save, M. Manguian, C. Chassenieux and B. Charleux, Macromolecules, 2005, 38, 280-289.
23 M. Tokuda, T. Sanada, T. Shindo, T. Suzuki and H. Minami, Langmuir, 2014, 30, 3406-3412.

24 A. F. Naves, R. R. Palombo, L. D. M. Carrasco and A. M. Carmona-Ribeiro, Langmuir, 2013, 29, 9677-9684.

25 W. Chin, C. Yang, V. W. L. Ng, Y. Huang, J. Cheng, Y. W. Tong, D. J. Coady, W. Fan, J. L. Hedrick and Y. Y. Yang, Macromolecules, 2013, 46, 8797-8807.

26 V. Bütün, S. P. Armes and N. C. Billingham, Macromolecules, 2001, 34, 1148-1159.

27 L. Timofeeva and N. Kleshcheva, Appl. Microbiol. Biotechnol., 2010, 1-18.

28 C. Abid, S. Chattopadhyay, N. Mazumdar and H. Singh, J. Appl. Polym. Sci., 2010, 116, 1640-1649.

29 D. Park, J. A. Finlay, R. J. Ward, C. J. Weinman, S. Krishnan, M. Paik, K. E. Sohn, M. E. Callow, J. A. Callow, D. L. Handlin, C. L. Willis, D. A. Fischer, E. R. Angert, E. J. Kramer and C. K. Ober, ACS Appl. Mater. Interfaces, 2010, 2, 703-711.

30 E.-R. Kenawy, S. D. Worley and R. Broughton, Biomacromolecules, 2007, 8, 1359-1384.

31 S. Förster, V. Abetz and A. E. Müller, in Polyelectrolytes with Defined Molecular Architecture II, ed. M. Schmidt, Springer, Berlin, Heidelberg, 2004, ch. 0005, vol. 166, pp. 173210.

32 S. Krishnan, A. Klein, M. S. El-Aasser and E. D. Sudol, Macromolecules, 2003, 36, 3152-3159.

33 A. M. Santos, A. Elaïssari, J. M. G. Martinho and C. Pichot, Polymer, 2005, 46, 1181-1188.

34 S. Kato, K. Sato, D. Maeda and M. Nomura, Colloids Surf., A, 1999, 153, 127-131.

35 C. Burguière, S. Pascual, C. Bui, J.-P. Vairon, B. Charleux, K. A. Davis, K. Matyjaszewski and I. Bétremieux, Macromolecules, 2001, 34, 4439-4450.

36 S. C. Abeylath and E. Turos, Carbohydr. Polym., 2007, 70, 32-37.

37 O. Otman, P. Boullanger, E. Drockenmuller and T. Hamaide, Beilstein J. Org. Chem., 2010, 6, 58.

38 H. Tobita, Y. Takada and M. Nomura, Macromolecules, 1994, 27, 3804-3811.

39 D. F. Sangster, J. Feldthusen, J. Strauch and C. M. Fellows, Macromol. Chem. Phys., 2008, 209, 1612-1627.

40 P. A. Steward, J. Hearn and M. C. Wilkinson, Adv. Colloid Interface Sci., 2000, 86, 195-267.

41 S. Lenoir, C. Pagnoulle, M. Galleni, P. Compère, R. Jérôme and C. Detrembleur, Biomacromolecules, 2006, 7, 22912296. 